\title{
Factorial Composition of the Self-efficacy in the Sociocultural Sphere Scale in College Freshmen
}

\author{
Yunuen Rangel, Jesus E. Peinado, Ramon Lugo, Francisco J. Flores* \\ Faculty of Physical Culture Sciences, Autonomous University of Chihuahua, Chihuahua, México
}

Email address:

fflores@uach.mx (F. J. Flores)

\section{To cite this article:}

Yunuen Rangel, Jesus E. Peinado, Ramon Lugo, Francisco J. Flores. Factorial Composition of the Self-efficacy in the Sociocultural Sphere Scale in College Freshmen. Psychology and Behavioral Sciences. Vol. 5, No. 1, 2016, pp. 1-6. doi: 10.11648/j.pbs.20160501.11

\begin{abstract}
The present study aims to investigate whether the psychometric results proposed by [1] for the Self-efficacy in the Sociocultural Sphere Scale replicate. The total sample was of 1545 subjects; 616 women and 929 men, first year students in the degrees offered at the Autonomous University of Chihuahua, with an mean age of 18.21 years $(\mathrm{SD}=0.73)$. The factorial structure of the questionnaire was analyzed by confirmatory factor analysis. The analysis shows that a two-factor structure is feasible and appropriate. The two-factor structure (Promotion of Culture and Cultural Identity), based on statistical and substantive criteria, has shown adequate fit indicators of reliability and validity. Furthermore, the results of the factor analysis conducted with subsamples, indicate the existence of strong evidence of the stability of the factor structure. Future research should replicate these findings in larger samples.
\end{abstract}

Keywords: Self-efficacy, Factorial Structure, Construct Validation, Structural Equation

\section{Introduction}

Self-efficacy refers to the belief that one can achieve the desired results and is a central construct in Bandura's social cognitive theory $[2,3]$. According to the theory, self- efficacy of an individual is a fundamental factor in the interaction between the environment and the behavior of the individual [3]. Self-efficacy can be specific or general. The specific self-efficacy describes the beliefs of an individual on which he can achieve good results in a defined area of his life, for example his academic performance. While the general self-efficacy is in an overall sense the individual's competence in handling a variety of life challenges. Both types of self-efficacy are relatively stable and can be characterized as traits [4].

The application of Bandura's theory of self-efficacy in the educational field shows how students with high self-efficacy expectations enjoy greater academic motivation [5-7]. Also, they obtain better results, they are more able to effectively self-regulate their learning and show greater intrinsic motivation when learning [8-10]. Consequently, improved self-efficacy expectations increases the motivation and performance in learning tasks [11]. Therefore, is not enough to be able to, you must judge yourself capable. Able to use the skills and personal strengths to a variety of circumstances, including emotional reactions that are experienced in difficult situations [12].

As an example of the importance of self-efficacy in the academic sphere, we can say that this reveals why people with the same level of skills and knowledge present behaviors and/or different results, or why people act in dissonance with their skills [13, 14]. This is because the adequate academic performance also depends on the perceived efficacy to successfully manage academic demands. Therefore, self-efficacy beliefs in one's ability are indispensable to master the academic activities; since students that trust in their capabilities are more motivated to achieve their goals [15]. Likewise, people who doubt in their capabilities can believe that things are more difficult than they really are, belief that generates stress, depression and a narrow vision to solve problems [16]. It has been shown that a low level of self-efficacy may be responsible of, not only reduced academic performance and interest in the study, but also inappropriate adjustment behaviors in young people [17], hence the importance that education strengthens the development of academic competence in students and encourage skills that enable them to believe in their own abilities [18, 19].

For all the above, this research is based on the premise that the perceived academic self-efficacy is an important mediating factor in how people feel, think, motivate and 
behave; so measuring the perception of academic self-efficacy in the learner is extremely important in the study of how to facilitate progress and educational success, as well as to minimize the risk of leaving [20,21].

This paper analyzes the internal consistency and the factor structure of a self-report instrument that allows to identify academic behaviors in the Sociocultural Sphere, whose level of perceived self-efficacy in the students represent an opportunity area; in relation to the rest of the students, providing evidence and data that promote the educational intervention within a perspective of attention to diversity in the classroom.

Therefore, the present instrumental study [22] is aimed to provide empirical support for the factorial division proposed by [1] for the Self-efficacy in the Sociocultural Sphere Scale; which it is justified by the importance of checking the factorial structure of the instrument and the psychometric equivalence of it in different groups; since in the context of intergroup comparison, it is essential to consider the need to conduct the adaptation of an instrument of psychological measure that would meet all the criteria of equivalence, but above all, consider whether the same factorial structure is applicable to different groups of subjects or, more generically, to different populations [23]. So in the present study, the interest is not only in the structure of the instrument, but also in the psychometric equivalence of it in different groups.

\section{Method}

\subsection{Participants}

The sample of 1545 subjects, 616 women and 929 men was obtained by a convenience sample, trying to cover the representation of the different degrees offered at the Autonomous University of Chihuahua. The age of participants ranged between 17 and 20 years, with a mean of 18.21 and a standard deviation of 0.732 years.

The sample was randomly divided into two parts using the Statistical Package for Social Sciences (SPSS) version 18.0; in order to perform parallel studies to corroborate and verify the results (cross validation).

The subsample 1 was composed by 743 subjects. Ages ranging between 17 and 20 years, with a mean of 18.18 and a standard deviation of 0.75 years.

The subsample 2 was composed of 802 subjects. Ages ranging between 17 and 20 years, with a mean of 18.23 and a standard deviation of 0.72 years.

\subsection{Instrument}

The self-efficacy in promotion of the culture and cultural identity was measured by the Self-efficacy in the Sociocultural Sphere Scale [1]. This questionnaire consists of a nine-item scale with two subscales: promotion of the culture (six items) and cultural identity (three items). According to previous studies $[12,24]$, due to the fact that in the mexican academic context students are commonly assessed by a scale from 0 to 10 , in the present study a Likert-type scale from 0 to 10 was chosen. For each domain (item) of the promotion of the culture and cultural identity (subscales), the participants were asked about how capable they feel, how much interest they have, and if they would make an effort to change how capable they will be to... Therefore, all the participants responded to each of the nine items (Table 1) of the questionnaire in the three different scenarios: (a) Scenario of perceived ability, responding in the context "how capable I feel to... to manage in each of the domains of the competences above mentioned"; (b) Scenario of interest in being able, responding in the context "how much interest I have in being able to... to manage in each of the domains of the competences above mentioned"; and (c) Scenario of change to be able to, responding into the context "if I would make an effort to change, how much capable I will be able to... to manage in each of the domains of the competences above mentioned".

\subsection{Procedure}

Students of the degrees offered at the Faculty of Physical Culture (FCCF) of the Autonomous University of Chihuahua were invited to participate. Those who agreed to participate signed the consent letter. Then, the instrument described above was applied using a personal computer (administrator module of the instrument of the scales editor of typical execution), in a session of about 25 minutes in the computer labs of the participating faculties. At the beginning of each session students were given a brief introduction on the importance of the study and how to access the instrument; they were asked the utmost sincerity and they were guaranteed the confidentiality of the data obtained. Instructions on how to respond were in the first screens; before the first instrument item. At the end of the session they were thanked for their participation. Once the instrument was applied, data was collected by the results generator module of scales editor, version 2.0 [25].

\subsection{Data Analysis}

The first step in analyzing the psychometric properties of the questionnaire was to calculate the mean, standard deviation, skewness, kurtosis and discrimination indexes of each item. Then remove of the scale those who obtain a kurtosis or extreme asymmetry, or a discrimination index below .35 .

Then, were submitted to comparison two models: Model 1 (M1), one-factor model and Model 2 (M2), which responds to a two-factor structure according to the original distribution of the items of the questionnaire.

To conduct the confirmatory factorial analysis, AMOS 21 software was used [26], variances in terms of error were specified as free parameters, in each latent variable (factor) a structural coefficient was set associated to one, so that scale was equal to one of the observable variables (items). The estimated method used was the maximum credibility; following the recommendation of [27], so when the confirmatory factorial analysis is used, it is necessary to verify 
not only the adjustment of the theoretical model but it is recommended to compare the fit indexes of some alternative models to select the best.

To evaluate the adjustment model, statistical chi-squared, the Goodness-of-fit index (GFI), and the root mean square error of approximation (RMSEA) were used as absolute adjustment measures. Adjusted goodness of fit index (AGFI) the Tucker-Lewis Index (TLI), the comparative fit index (CFI) as measures of increasing adjustment. The chi-squared fit index divided by degrees of freedom (CMIN/GL) and the Akaike Information Criterion (AIC) as adjusting measures of Parsimony [28, 29].

Subsequently, following the recommendations of [23], was made an analysis of the factorial invariance of the questionnaire for the subsamples, taking as a base the best measurement model obtained in the previous stage.

Finally was calculated the reliability of each of the dimensions, of the measurement models obtained in each subsample, through Cronbach's alpha [30, 31] and Omega coefficient $[32,33]$.

\section{Results}

Descriptive analyzes and discrimination indexes.

In Table 1 are summarized the results of the descriptive analysis and the discrimination indexes (total-item correlation corrected) of each of the 9 items on the questionnaire in the total sample. The answers to all items reflect mean scores ranging between 7.01 and 8.77, and standard deviation offers, in all cases, higher values than 1.20 (within a response range between 0 and 10). With the exception of the items 2 and 3, all values of skewness and kurtosis are within \pm 2.5 ; so is inferred that the variables are reasonably fit to a normal distribution. Regarding discrimination indexes of all items, they discriminate satisfactorily by discrimination indexes above 35 [34].

Confirmatory Factorial Analysis.

The global results of the confirmatory factor analysis in the subsample 1 (GFI .928; RMSEA .105; CFI .922) and the subsample 2 (GFI .935; RMSEA .101; CFI .936) for M1 model corresponds to a unifactorial distribution of the items in the questionnaire, indicate that the measurement model, in both subsamples is not acceptable (Table 2).

Table 1. Descriptive Analysis and discrimination indexes of the questionnaire items "Self-efficacy in the Sociocultural Sphere Scale". Total sample.

\begin{tabular}{llllll}
\hline Item & $\mathbf{M}$ & $\mathbf{S D}$ & $\mathbf{A S}$ & $\mathbf{C U}$ & $\mathbf{r}_{\mathrm{i} \text {-total }}$ \\
\hline Item 1 & 7.21 & 2.00 & -.94 & .90 & .66 \\
Item 2 & 8.84 & 1.29 & -2.05 & 7.35 & .40 \\
Item 3 & 8.46 & 1.51 & -1.62 & 3.98 & .54 \\
Item 4 & 8.12 & 1.76 & -1.29 & 1.97 & .41 \\
Item 5 & 7.01 & 2.16 & -.92 & .65 & .63 \\
Item 6 & 7.44 & 1.95 & -.96 & 1.09 & .73 \\
Item 7 & 7.50 & 1.83 & -.89 & .92 & .71 \\
Item 8 & 7.67 & 1.87 & -1.16 & 1.70 & .73 \\
Item 9 & 7.59 & 1.97 & -1.08 & 1.39 & .72 \\
\hline
\end{tabular}

Note: $\mathrm{M}=$ mean; $\mathrm{SD}=$ standard deviation; $\mathrm{AS}=$ asymmetry; $\mathrm{CU}=$ kurtosis; ri-Total $=$ total-item correlation corrected.

The factor of the model M1 explains approximately the $50.65 \%$ of the variance in the first sub-sample and the $53.66 \%$ of the variance in the second subsample. Besides, 4 of the 9 items saturate under .70 in their intended dimension (items 2, 3,4 and 5) both the first and second subsample.

The overall results of the confirmatory factor analysis in the first (GFI .986; RMSEA .038; CFI .991) and second subsample (GFI .982; RMSEA .047; CFI .988), of the second model tested (M2) that corresponds to a two-dimensional structure of the questionnaire, indicates that this measurement model is better than the previous model and its fit is optimal (Table 2). The two factors of this model explain altogether, in both sub-samples more than $60 \%$ of the variance.

Furthermore according to the results of Table $3 ; 3$ of the 9 items, in both subsamples saturate under .70 in their intended dimension. Also was observed moderate intercorrelations among factors, showing a not very adequate discriminant validity between them.

Table 2. Absolute, incremental and Parsimony fit indexes for the generated models. Subsamples 1 and 2.

\begin{tabular}{|c|c|c|c|c|c|c|c|c|}
\hline \multirow[b]{2}{*}{ Model } & \multicolumn{3}{|c|}{ Absolute indexes } & \multicolumn{3}{|c|}{ Incremental Indexes } & \multicolumn{2}{|c|}{ Parsimony Idexes } \\
\hline & $\chi^{2}$ & GFI & RMSEA & AGFI & TLI & CFI & CMIN/DF & AIC \\
\hline \multicolumn{9}{|c|}{ First factor solution (subsample 1) } \\
\hline M1 & $249.416^{*}$ & .928 & .105 & .880 & .896 & .922 & 9.238 & 285.416 \\
\hline M2 & $47.896^{*}$ & .986 & .038 & .972 & .986 & .991 & 2.082 & 91.896 \\
\hline \multicolumn{9}{|c|}{ Second factor solution (subsample 2) } \\
\hline M1 & $246.171^{*}$ & .935 & .101 & .891 & .915 & .936 & 9.117 & 282.171 \\
\hline M2 & $63.755^{*}$ & .982 & .047 & .965 & .981 & .988 & 2.772 & 107.755 \\
\hline
\end{tabular}

Note: $* \mathrm{p}<.05 ; \mathrm{GFI}=$ goodness of fit index; RMSEA $=$ root mean square error of approximation; AGFI = adjusted goodness of fit index; TLI $=$ Tucker-Lewis index; $\mathrm{CFI}=$ comparative fit index; $\mathrm{CMIN} / \mathrm{DF}=$ chi-squared fit index divided by degrees of freedom; AIC $=$ Akaike information criterion. 
Table 3. Standardized solutions confirmatory factor analysis for the M2 Model. Subsample 1 and 2.

\begin{tabular}{|c|c|c|c|c|}
\hline \multirow[b]{2}{*}{ Item } & \multicolumn{2}{|c|}{ Subsample 1} & \multicolumn{2}{|c|}{ Subsample 2} \\
\hline & F1 & F2 & F1 & F2 \\
\hline \multicolumn{5}{|l|}{ Factor weights } \\
\hline 7 Participate in proposals that contribute to the development and social and cultural improvement. & .81 & & .84 & \\
\hline 9 Act as a promoter of life quality. & .83 & & .82 & \\
\hline $\begin{array}{l}8 \text { Interact with different social groups promoting Interact with different social groups promoting } \\
\text { quality of life. }\end{array}$ & .80 & & .83 & \\
\hline 6 Generate an interaction with the environment, encouraging the community cultural level. & .78 & & .75 & \\
\hline 1 Actively participate in processes of creation, conservation and cultural diffusion. & .70 & & .77 & \\
\hline 5 Analyze the phenomena of globalization and sustainable development from different perspectives. & .64 & & .63 & \\
\hline 3 Show values towards the different customs and multicultural differences. & & .77 & & .70 \\
\hline 2 Act with respect and tolerance & & .61 & & .60 \\
\hline 4 Identify with the culture of my state and country. & & .50 & & .59 \\
\hline \multicolumn{5}{|l|}{ Correlations between factors } \\
\hline F1 & - & & - & \\
\hline F2 & .67 & - & .74 & - \\
\hline
\end{tabular}

Note: F1 = promotion of the culture; F2 = Cultural Identity.

Invariance of the factor structure between subsamples.

The fit indexes obtained (Table 4) allow to accept the equivalence of the basic measuring models between the two subsamples. Although the value of Chi-squared exceeds to that required to accept the hypothesis of invariance, the $\mathrm{GFI}=.984, \mathrm{CFI}=.990, \mathrm{RMSEA}=.030$ y $\mathrm{AIC}=199.651$ indexes contradict this conclusion allowing us to accept the base model invariance (unrestricted model).

Adding to the base model restrictions on factorial loads the metric invariance was characterized. The values shown in Table 4 allow accepting this level of invariance. The goodness of fit index (GFI .983) and root mean square error of approximation (RMSEA .028) continue to provide convergent information in this direction. Also, the Akaike Information Criterion (AIC 191.925) and Bentler comparative fit index (CFI .990) do not suffer large variations over the previous model. Using the criteria for the evaluation of the nested models proposed by Cheung and Rensvold [35], who suggest that if the calculation of the difference of the CFI of both nested models diminish in .01 or less, the restricted model is taken for granted therefore the compliance of the factorial invariance. The difference of the CFIs obtained allows accepting the metrical invariance model. We can conclude up to this point that factorial charges are equivalent in the two subsamples.

Table 4. Goodness of fit indexes of each of the models tested in the factorial invariance.

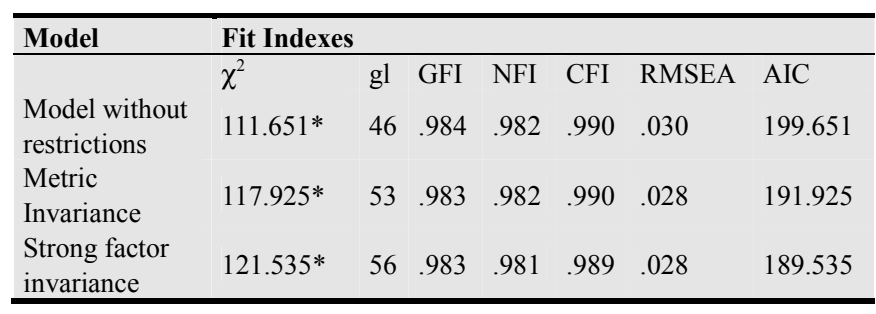

Note: ${ }^{*} \mathrm{p}<.05 ; \mathrm{GFI}=$ goodness of fit index; NFI = normed fit index; CFI = comparative fit index; RMSEA = root mean square error of approximation; $\mathrm{AIC}=$ Akaike information criterion.
Having demonstrated the metric invariance between the subsamples, we evaluate the equivalence between intercepts (strong factorial invariance). The Indices (Table 4) show a good adjustment of this model, evaluated independent as well as analyzed toward nesting with the metric invariance model. The difference between the two comparative indices of Bentler is .028; and the general adjustment index is .983 and the root mean square error of approximation is .028. Accepted then the strong invariance, the two evaluated models are equivalent toward the factorial coefficients and the intercepts.

The factors obtained in the confirmatory factor analysis, mostly all reached values above .70 of internal consistency in both samples; demonstrating adequate internal consistency for these type of subscales, particularly if it is considered the small number of items (Table 5).

Table 5. Coefficient omega and alpha for the factors obtained in exploratory factor analysis subsamples 1 and 2.

\begin{tabular}{lllll}
\hline & \multicolumn{2}{l}{ Subsample 1 } & \multicolumn{2}{l}{ Subsample 2 } \\
\hline Factor & $\Omega$ & $\alpha$ & $\Omega$ & $\alpha$ \\
Cultural Promotion & .89 & .89 & .90 & .90 \\
Cultural Identity & .66 & .63 & .66 & .64 \\
\hline
\end{tabular}

\section{Discussion and Conclusions}

The main objective of the study was to investigate whether or not the psychometric results proposed by [1] are replicate for the Self-efficacy in the Sociocultural Sphere Scale through a sample of university students using a confirmatory factor analysis (CFA). The confirmatory factor analysis conducted in each subsample separately, supports the factorial structure of two factors: promotion of the culture and cultural identity obtained by [1] that demonstrates an adequate internal consistency, particularly considering the small number of items in each; at the same time that the factors obtained present in general suitable standardized factor saturations, which correspond to those found in the study of [1]. Suggesting also the existence of strong evidence of 
cross-validation of the measure and therefore the stability of the structure until the contrary is proved.

In summary, the analysis of the psychometric properties of the Self-efficacy in the Sociocultural Sphere Scale, have shown, in this study as in the performed [1], that a two-factor structure is viable and appropriate in accordance with established psychometric requirements when informants are the students themselves. The structure of two factors, based on statistical and substantive criteria, has shown adequate indicators of adjustment, reliability and validity. However, the scope of these results is limited, and it is necessary further research to confirm the structure obtained, which will allow counting with more robust evidence regarding the factorial structure of the scale. Specifically, it must be demonstrated if the invariance of the structure of the scale is accomplished by gender, age, between students from different degrees, among others; so that, is considered that more studies are needed in order to confirm or refute the data obtained in investigations carried out so far.

It is also essential to check if the scale is useful to study the relationship between academic self-efficacy and learning.

\section{Acknowledgements}

This study is part of a project funded by the Secretaría de Educación Pública-Subsecretaría de Educación Superior-Dirección General de Educación Superior Universitaria de México [Mexican Ministry of Education-Department of Higher Education-General Directorate of the University Education] (OF-13-6894).

\section{References}

[1] F. Muñoz, M. C. Zueck, G. Gastélum, J. C. Guedea, Composición factorial de una escala de autoeficacia en el ámbito sociocultural en universitarios de ingeniería, Formación Universitaria, Vol. 5, pp. 39-50, 2012.

[2] A. Bandura, Social foundations of thought and action: A social cognitive theory, Prentice Hall, Englewood Cliffs, NJ, 1986.

[3] A. Bandura, On the functional properties of perceived self-efficacy revisited, Journal of Management, Vol. 38, pp. 9-44, 2012.

[4] G. B. Yeo, A. Neal, An examination of dynamic relationship between self-efficacy and performance across levels of analysis and levels of specificity, Journal of Applied Psychology, Vol. 91, pp. 1088-1101, 2006.

[5] S. D. Brown, S. Tramayne, D. Hoxha, K. Telander, R. W. Lent, Social cognitive predictors of college students' academic performance and persistence: A meta-analytic path analysis, Journal of Vocational Behavior, Vol. 72, pp. 298-308, 2008.

[6] G. V. Caprara, R. Fida, M. Vecchione, G. Del Bove, G. M. Vecchio, C. Barbaranelli, Longitudinal analysis of the role of perceived efficacy for self-regulated learning in academic continuance and achievement, Journal of Educational Psychology, Vol. 100, pp. 525-534, 2008.
[7] A. González, P. V. Paoloni, Self-determination, behavioral engagement, disaffection, and academic performance: A mediational analysis, Spanish Journal of Psychology, Vol. 17, pp. 1-10, 2014.

[8] M. Cartagena, Relación entre la autoeficacia y el rendimiento escolar y los hábitos de estudio en alumnos de secundaria, Revista Iberoamericana sobre Calidad, Eficacia y Cambio en Educación, Vol. 6, pp. 59-99, 2008.

[9] M. Salanova, S. Llorens, W.B. Shaufeli, "Yes, i can, i feel good, and i just do it!" on gain cycles and spirals of efficacy beliefs, affect, and engagement, Applied Psychology: An International Review, Vol. 60, pp. 255-285, 2011.

[10] M. Hasheminasab, Z. Ghanbari, J. Azizi, M. Shamsi, Investigating the relationship between self-efficacy with academic achievement, discipline, urban-rural and order birth of high school students in rafsanjan, International Journal of Psychology and Behavioral Research, Vol. 3, pp. 258-264, 2014.

[11] D. A. Adeyemo, Moderating influence of emotional intelligence on the link between academic self-efficacy and achievement of university students, Psychology Developing Societies, Vol. 19, pp. 199-213, 2007.

[12] H. Blanco, M. Martínez, M. d. C. Zueck, G. Gastélum, Análisis psicométrico de la escala autoeficacia en conductas académicas en universitarios de primer ingreso, Actualidades Investigativas en Educación, Vol. 11, pp. 1-27, 2011.

[13] A. Bandura, Self-efficacy mechanism inhuman agency, American Psychologist, Vol. 37, pp. 122-147, 1982.

[14] E. Pérez, C. Lescano, D. Heredia, P. Zalazar, L. Furlám, M. Martínez, Desarrollo y análisis psicométricos de un inventario de autoeficacia para inteligencias múltiples en niños argentinos Psicoperspectivas, Vol. 10, pp. 169-189, 2011.

[15] Á. Blanco, Creencias de autoeficacia de estudiantes universitarios: Un estudio empírico sobre la especificidad del constructo, RELIEVE, Vol. 16, pp. 1-28, 2010.

[16] M. Vera, M. Salanova, B. Martín-del-Río, Self-efficacy among university faculty: How to develop an adjusted scale, Anales de Psicología, Vol. 27, pp. 800-807, 2011.

[17] B. Zimmerman, A. Kitsantas, Homework practice and academic achievement. The mediating role of self-efficacy and perceived responsibility beliefs, Contemporary Educational Psychology, Vol. 30, pp. 397-417, 2005.

[18] M. Á. Carbonero, E. Merino, Autoeficacia y madurez vocacional, Psicothema, Vol. 16, pp. 229-234, 2008.

[19] M. Ornelas, H. Blanco, J. M. Rodríguez, F. J. Flores, Análisis psicométrico de la escala autoeficacia en conductas de cuidado de la salud física en universitarios de primer ingreso, Formación Universitaria, Vol. 4, pp. 21-34, 2011.

[20] A. A. Peguero, K. A. Shaffer, Academic self-efficacy, dropping out, and the significance of inequality, Sociological Spectrum, Vol. 35, pp. 46-46, 2015.

[21] R. Shkullaku, The relationship between self - efficacy and academic performance in the context of gender among albanian students, European Academic Research, Vol. 1, pp. 467-478, 2013. 
[22] I. Montero, O. León, Sistema de clasificación del método en los informes de investigación en psicología, International Journal of Clinical and Health Psychology, Vol. 5, pp. 115-127, 2005.

[23] J. Abalo, J. Lévy, A. Rial, J. Varela, Invarianza factorial con muestras múltiples, in: J. Lévy (Ed.) Modelización con estructuras de covarianzas en ciencias sociales Netbiblo, Madrid, 2006, pp. 259-278.

[24] J. Viciana, E. M. Cervelló, J. Ramírez, Effects of manipulating positive and negative feedback on goal orientation, perceived motivational climate, satisfaction, task choice, perception of ability, and attitude to physical education lessons, Perceptual and motor skills, Vol. 105, pp. 67-82, 2007.

[25] H. Blanco, M. Ornelas, J. L. Tristán, A. Cocca, D. Mayorga-Vega, J. López-Walle, J. Viciana, Editor for creating and applying computerise surveys, Procedia Social and Behavioral Sciences, Vol. 106, pp. 935-940, 2013.

[26] J. R. Arbuckle, Amos users guide version 21.0, Marketing Department, SPSS Incorporated, Chicago, IL, 2012.

[27] B. Thompson, Exploratory and confirmatory factor analysis. Understanding concepts and applications. American Psychological Association, Washington, D C, 2004.

[28] B. M. Byrne, Structural equation modeling with amos: Basic concepts, applications, and programming, Routledge, New York, NY, 2010.
[29] E. Gelabert, L. García-Esteve, R. Martín-Santos, F. Gutiérrez, A. Torres, S. Subirà, Psychometric properties of the spanish version of the frost multidimensional perfectionism scale in women, Psicothema, Vol. 23, pp. 133-139, 2011.

[30] P. Elosua, B. D. Zumbo, Coeficientes de fiabilidad para escalas de respuesta categórica ordenadas, Psicothema, Vol. 20, pp. 896-901, 2008.

[31] J. C. Nunnally, I. H. Bernstein, Teoría psicométrica, McGraw-Hill, México, 1995.

[32] W. Revelle, R. E. Zinbarg, Coefficients alpha, beta, omega and the glb: Comments on sijtsma, Psychometrika, Vol. 74, pp. 145-154, 2009.

[33] K. Sijtsma, On the use, the misuse, and the very limited usefulness of cronbach's alpha, Psychometrika, Vol. 74, pp. 107-120, 2009.

[34] P. Brzoska, O. Razum, Validity issues in quantitative migrant health research: The example of illness perceptions, Peter Lang International Academic Publishers, New York, NY, 2010.

[35] G. W. Cheung, R. B. Rensvold, Evaluating goodness-of-fit indexes for testing measurement invariance, Structural Equation Modeling, Vol. 9, pp. 233-255, 2002. 